\title{
Cooperative Learning as a Valuable Approach to Teaching Translation
}

\author{
Marina V. Melnichuk - Valentina M. Osipova
}

\section{DOI: 10.18355/XL.2017.10.01.03}

\begin{abstract}
In the process of rapid exchange of information and cross-cultural communication, translation is playing an increasingly important role. It is regarded as a constructive skill-enhancing tool. The paper reports the results of the research work aimed to evaluate the use of the cooperative learning (CL) technique for teaching translation in authentic classroom situation at a non-linguistic institution of higher education. We have been able to explore the value of the translation methodology "Cooperative Work Procedure" proposed by Prof. Gerding-Salas C. (Gerding-Salas, 2000). Research on collaboration compared group performance to individual performance as well as identified interactions within heterogeneous groups. The current study proves that both students and educators may benefit from CL. The paper focuses on the advantages of this method. The research used both quantitative and qualitative methods. The findings show that CL technique is highly suitable for the use in the translation class. Learning process evolves dynamically; the discussion stimulates criticism involving a fuller range of translation solutions and improvements and may lead into related topics for debate and discovery.
\end{abstract}

Key words: cooperative learning, cooperative work procedure, training translation, heterogeneous grouping

\section{Introduction}

\section{Training Translation Course}

The ever-growing globalization and the development of open knowledgebased economy have led to an enormous demand for highly skilled workforce equipped with both hard skills and soft skills. One of the main hard skills is a proficiency in a foreign language. Soft skills, on the other hand, are subjective skills. Also known as "people skills", soft skills relate to the ability to be a team player and communicate with team members. The University plays an important role in training young people who are able in their professional areas as well as proficient in English language and communication. Being a non-linguistic institution of higher education, the Financial University offers a translation course to undergraduates as an optional course. The course is aimed at improving English knowledge as well as providing soft skills needed by the graduates to supplement their bachelor's/master's degrees. Objectives of the course are as follows: to develop the student's insight into the nature and significance of translation; to stimulate an intellectual and linguistic challenge in the student; to offer a forum for dialogue and exchange of ideas and experiences; to raise the student's linguistic competence; to show how to apply translation tools and solutions; to teach real-life work translations.

\subsection{Literature Review}

The idea of the most renowned translation scholars that the judicious use of translation might be beneficial for students and can be a constructive skill-enhancing tool now seems entirely natural and obvious. Nowadays, when knowledge has been 
increasingly expanding and international communication has been intensifying, the phenomenon of translation has become fundamental. Be it for scientific, medical, technological, commercial, legal, cultural or literary purposes, today human communication depends heavily on translation and, consequently, interest in the field is also growing.

The review of the literature reveals that there has been much interest in the translation process itself, not the teaching of it. Many studies in Europe and some in America and England have been conducted in this respect. The translation theories introduced dramatic changes in notions of equivalence, faithfulness, the importance of context and function, translation strategies for different types of text, cultural interaction and conflict. Translation is considered not only as a linguistic activity, but as an economic activity and an intercultural communication activity. Nevertheless, there are only a few papers offering some practical ideas as how to teach translation. The publications covering striking problems facing translation instructors - what to be taught, how to teach translation skills and strategies, and how to promote students' motivation to learn translation - are rather scarce. Teaching translation is a real problem since one has to teach translation skills, techniques, and doing translation practice, both oral and written, within a limited time span. (Alekseeva, 2000). Past translators generally adopted the traditional teacher - centered method which involved giving the students a text to translate and marking the resulting production in terms of "correctness". This method derives from the old Latin-based method and it has been criticized by many scholars, Irma Sorvali being one of them. She says that "teaching translation in terms of correctness is not a teaching but a form of language testing, which is admittedly important but should not be an end in itself" (Sorvali, 1998). Daniel Gouadec identifies 3 factors which determine teaching of translation: the perception of what the functions of translators are; the training context; the strategies (Gouadec, 2007). González Davies finds that traditional translation classrooms are usually teacher- and text-centered and writing-based, without consideration of class dynamics and interaction (González, 2004). Despite a number of advantages of traditional translation teaching method, it is clear and evident: the old grammar and translation method (GTM) should be rejected and translation instruction should be designed beyond the conventional form. Researchers interested in this field put forward various kinds of theories on what is needed to do this work well (Nechayeva and Novitskaya, 2012). After the turn of the millennium, cooperative techniques in the translation classroom have become quite widespread. The research in the field of cooperative learning (CL) increased over the last decade. It revealed the effectiveness of cooperative learning in such areas as education, management, psychology, business. The literature on cooperative knowledge exploded in volume and importance. The articles included normative and empirical sections and provided focus and clarity to the area. CL is considered as one of the active teaching forms. Introduced in the 1980's, it continues to be a valuable teaching tool in terms of motivation, output and quality of work (Rodger et al., 2007). Gerding-Salas provides a neat list of possible exercises under the heading of "Cooperative Work Procedure" (Gerding-Salas, 2000). James A. Duplass points out the most commonly found characteristics of cooperative learning (Duplass, 2006).

\subsection{The key elements of cooperative learning in translation}

Cooperative learning in translation is an educational approach to teaching and learning that implies that students work both individually and together to complete a translation work. CL approach is based on the idea that learning is a 
naturally social act in which the participants talk among themselves. It is mainly through the discussion that learning occurs. The teacher monitors group activity and guides discussion if necessary.

In a cooperative learning, learners have the opportunity to converse with peers, present and defend ideas, exchange diverse beliefs, and question other conceptual frameworks. Learners benefit when exposed to diverse viewpoints from people with varied backgrounds. It is an active process whereby learners assimilate, process and synthesize information rather than simply memorize and reproduce it.

To realize the effective group work, it is essential to include the features of cooperative learning. There are five main features of cooperative learning: (a) positive interdependence; (b) face-to-face interaction; (c) interpersonal and small group skills; (d) individual accountability; and (e) small and heterogeneous groups.

Johnson, Johnson and Holubec asserted that positive interdependence is the first and the most important element of cooperative learning (Johnson et al., 2002). In their opinion, when students believe that they sink or swim together, learning activities become meaningful (Johnson and Johnson, 1994) and the students become an alternative source of positive reinforcement for one another. According to Johnson and Johnson, positive interdependence can be achieved through mutual goals (goal interdependence); sharing materials, resources, or information with group members (resource interdependence); division of labor (task interdependence); assigning complementary and interconnected roles (role interdependence); and giving a joint reward (reward interdependence). These interdependences can make students aware of what they need from each other, and collaboration can take place (Johnson and Johnson, 1994).

To create positive interdependence, the current study uses goal-, task- and role-interdependences. The students cooperate, support and help each other; each student needs to play two roles: when he/she is translating the text, he/she acts as a Translator; when he/she is reviewing another translator's work, he/she plays a comment-giving peer.

The second feature goes to face-to-face interaction. Face-to-face interaction engages students in higher-level thinking skills, such as analyzing, explaining, synthesizing, and elaborating (Hilke, 1990). With face-to-face interaction, knowledge can be comprehended better through students' stimulating talk and the integration of various views. It contributes to enhanced learning through error analysis, translation criticism, explaining, and problem-solving.

The third feature is connected with social skills: students must possess interpersonal, non-confrontational skills that are necessary to ensure quality cooperative learning.

The fourth feature is individual accountability, which should not be neglected because when members have a sense of personal responsibility, they will contribute their shares to the group's success (Hilke, 1990). The participants are accountable for their share of the work, thus equal contribution is provided.

Finally, the fifth distinguishing feature contributing to the effective group learning is heterogeneity of the group (Johnson and Johnson, 1994). Heterogeneous groups including students of diverse ability levels and backgrounds are most conducive for elaborate thinking, more frequent giving and receiving of explanations, and wider perspectives in discussing materials. Johnson and Johnson claimed that this kind of grouping increases the depth of understanding, the quality of reasoning, and the accuracy of long-term retention (Johnson and Johnson, 1994). Therefore, 
heterogeneous grouping can be used in a cooperative translation task to help students elaborate on their opinions and examine the materials from multiple perspectives.

\section{Methodology}

This study focuses on a method called "Cooperative Work Procedure" which was implemented in the translation classroom. The initial hypothesis was that "Cooperative Learning Procedure" technique was highly valuable for teaching translating. This study aimed, firstly, to evaluate the above-mentioned approach when applied in the translation classroom with students working in a critical, analytical manner rather than within authoritative frames; secondly, to determine interaction patterns and assess interpersonal communication and collaboration within groups; finally, to discuss the effectiveness of cooperative learning approach in teaching translation.

The research used both quantitative and qualitative study methods. The participants were students from three types of groups featuring a wide range of abilities.

The resulting quantitative findings were followed by the qualitative analysis. The completed translation work and items from the questionnaire were used as input data for the qualitative analysis. The teaching procedure included the following steps recommended by Gerding-Salas (Gerding-Salas, 2000):

- The selection of the text was made taking into account the professional area of students, i.e. the topic was familiar to them. Its length was 5,860 characters and it contained enough contextual information on the topic. Specialized terminology was also necessary in the selected text.

- The students read the text (on the paper carrier) twice: the first reading was general, i.e. to understand the text message. They worked to grasp the sense of a message, taking into consideration that they were translating neither words nor language but the whole text. The second reading was deep reading placing emphasis on terms and unclear places.

- The instructor divided the text into as many segments as students in the group. (In this study each group included 7 students). Then each student was assigned a part of economic text (about 800-900 characters) to be translated in the classroom.

- The students proceeded to transfer SL units to TL units. It was a preliminary translation of the assigned segment.

- After completion of the rough version, the students produced a written draft of translation using proper strategies and solutions to correctly transfer the meaning of the text.

- With the original text in front of her/him and being careful to follow the same correlative order of the ST, each student was required to read out his/her version of the translated segment. The students and instructor carefully followed the reading. Everybody could stop the reading at the end of the given sentence when the situation needed comments, questions, and contributions. During the discussion the students compared solutions and choose the best alternative.

- The students guided by the instructor checked the homogeneity of the terms and the coherence and cohesion of the final version.

- As a metacognitive activity, the students, assisted by the instructor, analyzed the applied translation strategies and procedures.

- The students amended the final version in the light of the whole text, formatted their version according to the original and mailed it to the instructor. 
- The instructor made a final revision and evaluated students' work along with giving constructive comments.

After translating the text, the students were given the questionnaire of 15 items addressing the components necessary to assess cooperative learning such as group processing, motivation, competition, dependability, accountability, interactivity and the use of collaborative skills.

In order to assess individual activity and involvement in task, the study monitored interactions within three different types of groups: heterogeneous groups with a wide ability range (including high-, medium-, and low-ability students), heterogeneous groups with a narrow ability range (combining high- with mediumability or medium- with low-ability). The study shows that the patterns of interaction varied across groups. The criteria for rating included: contribution, creativity, intuition, resourcefulness as well as communication skills (being a good listener and communicating respectfully).

\section{Results and Discussion}

\subsection{Quantitative Analysis}

The quantitative study was conducted with 84 students divided into 12 groups. It was aimed at investigating how the Cooperative Learning Procedure technique worked in translation class as well as assessing interaction patterns within different groups. Here we present the general findings that focus on the positive (see Table).

\subsubsection{Positive responses on cooperative learning}

Table 1 shows that a majority of the respondents appreciate the possibility to communicate while discussing the subject topic with $38.8 \%$ Agree and $53.1 \%$ Strongly Agree to the statement "I improve my communication skills when participating in discussion". The respondents clearly express their willingness to speak and exchange ideas in a group work with a majority agreed to the statement "I like to share ideas with mates". Table 1 also shows that the respondents agree that group work significantly facilitates the translation work. The obtained answers show that the respondents are driven in achieving higher performance. The respondents liked the opportunity to edit the produced text with a very high $62.1 \%$ Agree and $33.9 \%$ Strongly Agree to the statement "I like to revise and improve the translated text". The respondents are aimed at higher achievements with high percentage of Agree and Strongly Agree to the statement "I know that all students aim to get a high grade for the translation course". The majority of the respondents agree that group work contributed to better understanding of the text message and unclear places. Respondents agree to the benefits of group work in a translation task, they argued that group work promoted good partnership relations and cooperation among members with $60.9 \%$ Strongly Agree and 31.9\% Agree on the statement "Working in a group fosters good relations". 
Table 1. The percentage of positive responses on cooperative learning

\begin{tabular}{|c|c|c|c|c|}
\hline $\begin{array}{l}\text { Responses on cooperative } \\
\text { learning }\end{array}$ & $\begin{array}{l}\text { Stron } \\
\text { gly } \\
\text { Disag } \\
\text { ree }\end{array}$ & $\begin{array}{l}\text { Disag } \\
\text { ree }\end{array}$ & $\begin{array}{l}\text { Strongly } \\
\text { Agree }\end{array}$ & Agree \\
\hline $\begin{array}{l}\text { Article I. Develop } \\
\text { communication skills }\end{array}$ & $\begin{array}{l}6.5 \\
0\end{array}$ & $\begin{array}{l}1.6 \\
0\end{array}$ & $\begin{array}{l}53.1 \\
52.2\end{array}$ & $\begin{array}{l}38.8 \\
7.8\end{array}$ \\
\hline $\begin{array}{l}\text { Article II. Contribute } \\
\text { to better understanding of the } \\
\text { source text }\end{array}$ & 4.8 & 2.4 & 60.9 & 31.9 \\
\hline $\begin{array}{l}\text { Article III. Create good } \\
\text { relations among team players }\end{array}$ & 0.7 & 2.7 & 76.3 & 20.3 \\
\hline $\begin{array}{l}\text { Article IV. Motivate to } \\
\text { speak and exchange ideas }\end{array}$ & 0 & $\begin{array}{l}1.6 \\
3.2\end{array}$ & $\begin{array}{l}54.3 \\
37.2\end{array}$ & $\begin{array}{l}44.1 \\
59.6\end{array}$ \\
\hline $\begin{array}{l}\text { Article V. Facilitate the } \\
\text { translation work }\end{array}$ & 0 & 4 & 62.1 & 33.9 \\
\hline $\begin{array}{l}\text { Article VI. Enable to } \\
\text { find proper translating solutions }\end{array}$ & 2.1 & 1.6 & 46.8 & 49.5 \\
\hline $\begin{array}{l}\text { Article VII. Allow to } \\
\text { gain editing skills }\end{array}$ & & & & \\
\hline $\begin{array}{l}\text { Article VIII. Focus on } \\
\text { higher performance }\end{array}$ & & & & \\
\hline
\end{tabular}

\subsubsection{Characteristics of interactions}

In groups featuring a wide range of abilities, high- and low-ability students tended to form instructor-student relationships, practically leaving medium-ability students off task. Medium-ability students in these groups provided fewer explanations than the other participants.

In mixed groups with a narrow range of abilities, medium-ability students were much more active. In this type of group, all students participated actively, there were more questions eliciting help, and medium-ability students provided more explanations and demonstrated higher performance (see Fig.1). 


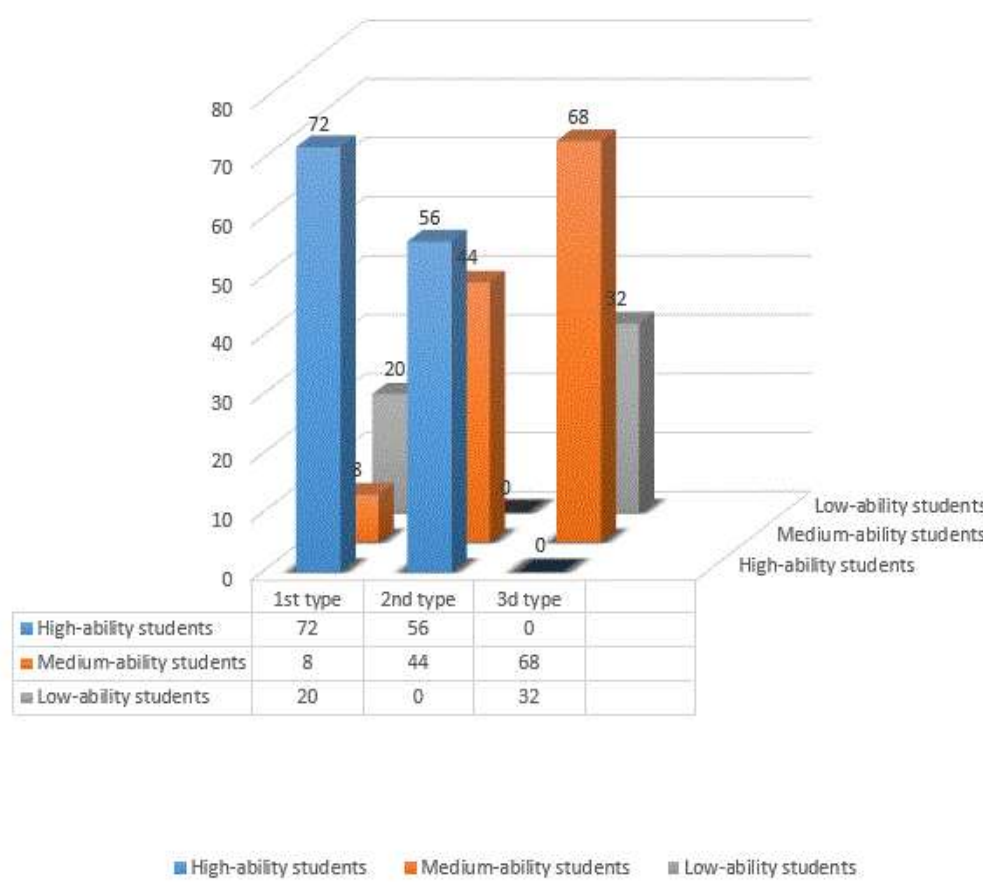

\section{Fig.1. Involvement in the task}

\subsection{Qualitative Analysis}

Quantitative data were used as an empirical support for qualitative study. Inviting our students to fill in the structured questionnaire, we tried to give as much voice as possible to the students themselves. The analysis of completed translations and responses from the questionnaire shows positive aspects of cooperative activity. The possibility to discuss and exchange ideas made it easier to understand the source material better and enabled to acquire familiarity with terminology and various kinds of translation solutions.

"The ability to discuss translation solutions in an objective way is central to a translator's competence" (Kussmaul, 1995: 33). Moreover, this method of instruction allows to develop and sharpen student communication skills and social development. Acting within a heterogeneous group, the students interact with those mates who are proficient in English language and translating skills. Cooperative learning makes it possible to work within a team and the students attempt to approach the language proficiency of their peers. The group dynamic creates a supportive environment for learning and helps foster collaboration and good partnership relations. 


\section{Conclusions}

\subsection{The pedagogical value of CL method}

The hypothesis set out at the beginning of the research work was confirmed experimentally. It permits us to conclude that the translation methodology "Cooperative Work Procedure" proposed by Prof. Gerding-Salas C. (Gerding-Salas, 2000) as a technique for teaching translating has proved to be successful. Its usefulness in teaching translation has been supported in this work. The method ensures training translators more suitably for the market needs. Students participate in team work and this prepares them to the real professional activities.

We have been able to explore the pedagogical value of this approach by applying it in 12 mixed groups. The research work demonstrates that a number of factors influence student learning, including individual characteristics, group composition, and task assignment. Patterns of interaction as well as the effects on subsequent performance vary across different groups: students participating more actively appear to benefit more from cooperative learning than members who don't contribute to the discussion. Similarly, high-ability students may participate more actively than low-ability students. Group composition is also an important factor. Thus, heterogeneous groups featuring a narrow ability range appear the most successful. Having students of different levels of abilities requires developing a training material that works for all of them. The selected texts must not be too easy or too difficult for the students because, if not, they will easily lose motivation. In such a case, learning will not occur. The educator should guide the students and warn them about possible "dangers". However this guidance needs to be very subtle: the educator will phrase the explanations more as enlightening suggestions rather than strict rules.

Learning flourishes in a social environment where conversation between learners takes place. In the collaborative learning environment, the learners are challenged both socially and emotionally as they listen to different perspectives, and are required to articulate and defend their ideas. In so doing, the learners begin to create their own unique conceptual frameworks and not rely solely on an expert's or a text's framework.

The present study finds that students should be encouraged to discuss while searching for equivalence in meaning to broaden their competence in the mother tongue and the foreign language and to develop their insight into the nature and significance of translation. CL is linked to a number of important educational outcomes, including critical thinking and motivation. CL approach also promotes metacognitive discourse among students to the extent that students are able to provide elaborated explanations and make their thinking and reasoning visible. In turn, students with strong metacognitive skills can serve as models of self-regulated learning for their group mates. The research also found a positive relationship between the degree to which grades are important to the students and their active participation in a cooperative learning. CL technique improves academic achievements. The CL method, which provides ways of arguing on the decisions and defending the choice, permits to develop during the training such desirable qualities of translators as self-awareness and self-confidence.

\subsection{Future lines of research}

Further research should be needed to refine some aspects of the method. The same experiment could be repeated with other groups of students in order to compare and contrast the results obtained. 
In the long run further steps to the original CL procedure can be added (e.g. on-line learning platforms) with a view to adapt it to ever-changing job market.

\section{Bibliographic references}

ALEKSEEVA, I.S. 2000. Professional Training for Translators. St-Petersburg: IFL.

DUPLASS, J. 2006. Middle and High School Teaching: Methods, Standards, and Best Practices. New York: Houghton Mifflin. ISBN 0-618-43575-1

GERDING-SALAS, C. 2000. Teaching translation - problems and solutions. Translation Journal, vol. 4 n. 3, pp. 1-11.

GONZALEZ DAVIES, M. 2004. Multiple Voices in the Translation Classroom. Amsterdam: John Benjamins Publishing Company. ISBN 9789027216618

GOUADEC, D. 2007. Translation as a profession. Amsterdam: John Benjamins Publishing. ISBN 9789027216816

HILKE, E. V. 1990. Cooperative learning. Bloomington, Indiana: Phi Delta Kappa Educational Foundation.

JOHNSON, D. W. - JOHNSON, R. T. - HOLUBEC, E. J. 2002. Cooperative Learning in the Classroom. Alexandria, VA: Association for Supervision and Curriculum Development.

JOHNSON, D. W. - JOHNSON, R. T. 1998. Together and Alone. Cooperative, Competitive, and Individualistic Learning (5th edition). Pearson. ISBN-13 9780205287710

KHOTABA, E. - TARAWNEH, K. 2015. Lexical Discourse Analysis in Translation. Journal of Education and Practice, vol. 6, n. 3, pp. 106-112. ISSN 2222-1735

KUSSMAUL, P. 1995. Training the Translator. Amsterdam/Philadelphia: John Benjamins Publishing Company. ISBN 9789027216090

NECHAYEVA, YE. - NOVITSKAYA, YU. 2012. Challenges in teaching translation. The Kazakh-American Free University Academic Journal, n. 4, pp. 187-192. ISSN 2153-926X

RODGER, S. - MURRAY, H. - CUMMINGS, A. 2007. Gender differences in cooperative learning with university students. The Alberta Journal of Educational Research, vol. 53, n. 2, pp. 157-173. ISSN1923-1857

SORVALI, I. 1998. The Translator as a Creative Being with special regard to the translation of literature and LSP. Babel, vol. 44, n. 3, pp. 234-243. ISSN 0521-9744

WANG, J. 2014. Characteristics of Economic Literature and its Translation. Theory and Practice in Language Studies, vol. 4, n. 4, pp. 786-791. ISSN 1799-2591

YANG, W. 2010. Brief Study on Domestication and Foreignization in Translation. Journal of Language Teaching and Research, vol. 1, n. 1, pp. 77-80. ISSN 1798-4769

Words: 3651

Characters: 25146 (13, 94 standard pages)

Marina Vladimirovna Melnichuk, PhD.

Assoc. Prof. Valentina Mihkailovna Osipova

Department "Foreign Languages - 3"

Financial University under the Government of the Russian Federation

Leningradsky prospect 49

125993 Moscow

Russia

mvmelnichuk@gmail.com

valentinaios-2012@yandex.ru 